\title{
Technical note: Validation of candidate reference genes for normalization of quantitative PCR in bovine mammary epithelial cells responding to inflammatory stimuli
}

\author{
S. Bougarn, P. Cunha, F. B. Gilbert, F. Meurens, and P. Rainard ${ }^{1}$ \\ INRA, UR1282 Infectiologie Animale et Santé Publique, 37380 Nouzilly, France
}

\begin{abstract}
Mammary epithelial cells (MEC) participate in the first line of defense of the mammary gland to invading pathogens. In vitro culture of MEC is widely used as a model to study the capacity of these cells to sense and respond to mastitis-causing bacteria. Analysis of gene expression by quantitative PCR (qPCR) following exposure to bacteria or bacterial constituents is a powerful tool to assess responses of MEC to pathogens. Although internal standards such as reference genes are required for $\mathrm{qPCR}$ to yield valid data, the validation of proper genes to quantify mRNA transcripts in MEC exposed to pro-inflammatory stimuli has never been reported. In this study, 10 commonly used reference genes belonging to different functional classes $(A C T B$, ATP5B, EIF2B2, GAPDH, PPIA, SDHA, SUZ12, UXT, $Y W H A Z$, and $18 s$ rRNA) were analyzed by qPCR to determine the most stable in bovine MEC unstimulated and stimulated with mastitis pathogens (Staphylococcus aureus or Escherichia coli), microbial agonists of the innate immune system (lipoteichoic acid and muramyl dipeptide, or lipopolysaccharide), or proinflammatory cytokines (IL-17A and tumor necrosis factor- $\alpha$ ). An $M$ value was used as a measure of gene stability as determined using the geNorm application. This study demonstrated that the expression of the 10 reference genes was stable under the different experimental conditions. These data will be useful for bovine mastitis research in selecting reference genes and validating reverse transcription-qPCR data.
\end{abstract}

Key words: mammary epithelial cells, qPCR, normalization, reference genes, innate immunity

\section{Technical Note}

In vitro cultures of bovine mammary epithelial cells (bMEC) have been widely used as a model to inves-

Received September 24, 2010.

Accepted January 27, 2011.

${ }^{1}$ Corresponding author: pascal.rainard@tours.inra.fr tigate the innate immune responses of the mammary gland to mastitis-causing pathogens (Goldammer et al., 2004; Wellnitz and Kerr, 2004; Strandberg et al., 2005; Lahouassa et al., 2007; Griesbeck-Zilch et al., 2009; Swanson et al., 2009). The capacity of bMEC to sense bacteria or bacterial products and the nature of the induced responses have been investigated mainly by measuring the modulation of gene expression following exposure of bMEC to whole bacteria or to bacterial constituents. Altered patterns of gene expression are conveniently characterized by using microarrays, but reverse transcription quantitative PCR (RT-qPCR) remains the most sensitive technique for the detection of mRNA targets. The specificity and dynamic range of $\mathrm{qPCR}$ make it the method of choice for measuring gene expression variations (Bustin et al., 2005, 2009). However, it has become clear that many pitfalls along the entire RT-qPCR workflow can lead to erroneous or biologically irrelevant results and conclusions (Bustin and Nolan, 2004). Among the requirements for valid RT-qPCR, normalization of data is an important step. It is now advocated that the use of internal reference genes is the most appropriate solution to the normalization issue (Bustin et al., 2009). Reference genes should be stably expressed, and such expression has to be experimentally validated. Complete invariance is probably only a theoretical view, and useful reference genes may vary according to both the cell type and experimental conditions. In principle, validation must be checked for every cell type and experimental condition, and the use of several reference genes for normalization is advocated to minimize the influence of individual reference gene variation (Bustin et al., 2009). Different reference genes have been used so far to normalize qPCR data obtained with bMEC, but in most cases they were not validated (Wellnitz and Kerr, 2004; Lahouassa et al., 2007; Swanson et al., 2009). In one study, the expression of one reference gene has been checked (Strandberg et al., 2005), and reference genes have been validated in studies dealing with mammary tissue under metabolic or hormonal influence (Bionaz and Loor, 2007; Kadegowda et al., 2009). Thus, the 
need exists for validation of candidate reference genes appropriate to the normalization of $\mathrm{qPCR}$ data from bMEC submitted to pro-inflammatory stimuli.

The aim of the present study was to identify and validate reference genes by evaluating the stability of 10 bovine candidate genes preselected from commonly used genes. Gene expression by bMEC exposed to diverse stimulation conditions representative of exposure to bacteria and to proinflammatory cytokines was measured by $\mathrm{qPCR}$. To take into account biological variation, cells from 5 different cows were used. The Minimum Information for Publication of Quantitative Real-Time PCR Experiments guidelines (MIQE; Bustin et al., 2009) were respected to treat samples and perform experiments.

Bovine MEC were isolated from 5 lactating cows (Holstein breed) and cryopreserved in liquid nitrogen as described previously (Lahouassa et al., 2007). When needed, bMEC were thawed and cultured without serum and antibiotics in D-MEM/F12 Advanced medium (Gibco, Invitrogen, Carlsbad, CA), which contained insulin $(10 \mu \mathrm{g} / \mathrm{mL})$, albumin $(0.4 \mathrm{mg} / \mathrm{mL})$, and transferrin $(7.5 \mu \mathrm{g} / \mathrm{mL})$, supplemented with $2 \mathrm{~m} M$ L-glutamine, $10 \mathrm{ng} / \mathrm{mL}$ IGF-1 (Peprotech, Rocky Hill, NJ), $5 \mathrm{ng} / \mathrm{mL}$ fibroblast growth factor (Peprotech), $5 \mathrm{ng} / \mathrm{mL}$ human recombinant epidermal growth factor (Sigma-Aldrich, St. Louis, MO), $1 \mu \mathrm{g} / \mathrm{mL}$ hydrocortisone (Sigma), and $20 \mathrm{~m} M$ HEPES (Cambrex Biowhittaker, East Rutherford, NJ). Cells were used at their third passage. Cells were seeded in 12-well tissue culture plates at a density of $2 \times 10^{5}$ cells/well and cultured until confluence; then, the growth medium was replaced with stimulation medium composed of D-MEM/F12 Advanced medium with $2 \mathrm{~m} M$ L-glutamine, $20 \mathrm{~m} M$ HEPES, and $4 \mathrm{ng} / \mathrm{mL}$ hydrocortisone as additives. Cells were characterized by immunocytochemistry by using monoclonal antibodies (Sigma). More than $90 \%$ of cells were labeled with antipan-cytokeratin, and 2 to $5 \%$ of cells were labeled with anti- $\alpha$-smooth muscle actin antibodies. Stimulation of bMEC was achieved with bacterial agonists of the innate immune system or with live bacteria. Staphylococcal lipoteichoic acid (LTA) and synthetic $N$-acetylmuramyl-L-alanyl-D-isoglutamine (muramyl dipeptide, MDP) were from InvivoGen (Toulouse, France). They were used in combination as they were shown to have a synergistic activity on bMEC (Bougarn et al., 2010). Lipopolysaccharide (Escherichia coli 055:B5) was from Sigma-Aldrich. The lyophilized LTA, MDP, and LPS were solubilized in sterile pyrogen-free water, and then diluted in cell culture medium. Staphylococcus aureus strain Newbould 305 and one Escherichia coli strain (H06) isolated from natural cases of bovine mastitis were prepared as described previously (Lahouassa et al., 2007). Two pro-inflammatory cytokines were also used as stimulants: bovine tumor necrosis factor- $\alpha$ (TNF- $\alpha$; AbD Serotec, Oxford, UK) and bovine IL17A [S. Bougarn, P. Cunha, F. Gilbert, A. Harmache, G. Foucras, and P. Rainard (all from INRA, Nouzilly, France), unpublished data]. Stimulations were carried out 16 to $24 \mathrm{~h}$ later. After removing medium, bMEC were stimulated with either $1 \mu \mathrm{g} / \mathrm{mL}$ LTA+MDP for 2 or $8 \mathrm{~h}, 20 \mu \mathrm{g} / \mathrm{mL}$ LPS for 3 or $6 \mathrm{~h}$, or $200 \mathrm{ng} / \mathrm{mL}$ recombinant bovine IL-17A in combination with $10 \mathrm{ng} /$ $\mathrm{mL}$ TNF- $\alpha$ for 1 or $6 \mathrm{~h}$; or live Staph. aureus (Newbould $305)$ or E. coli (strain H06) $\left(10^{7} / \mathrm{mL}\right.$ of either) for $5 \mathrm{~h}$, in stimulation medium. Control wells were treated with stimulation medium only. At indicated times after exposure to different stimuli, cell monolayers were washed twice with Hanks' balanced salt solution, and cells were harvested for RNA extraction.

Total RNA was extracted from bMEC using the NucleoSpin RNA II extraction kit (Macherey-Nagel, Düren, Germany) as described by the manufacturer. Residual genomic DNA was removed using DNase digestion with RNase-free DNase (Macherey-Nagel). Total RNA quantity and quality were assessed using a NanoDrop spectrophotometer (NanoDrop Technologies, Wilmington, DE). Then, RNA quantification was verified by agarose gel and by evaluating the $28 \mathrm{~S}$ and $18 \mathrm{~S}$ ribosomal RNA bands. The integrity of RNA was analyzed using the Agilent Bioanalyzer system (Agilent Technologies Inc., Santa Clara, CA). All samples had an RNA integrity number $>8$ except for some of the bMEC samples incubated with live bacteria, which gave an RNA integrity number around 5, values considered as suitable for qPCR (Fleige and Pfaffl, 2006). Total RNA $(1 \mu \mathrm{g})$ was then reverse transcribed to cDNA: 1 $\mu \mathrm{g}$ of RNA was incubated with $1 \mu \mathrm{g}$ of random primers (Promega, Madison, WI) for $10 \mathrm{~min}$ at $65^{\circ} \mathrm{C}$ and then for $5 \mathrm{~min}$ on ice, in a final volume of $10 \mu \mathrm{L}$. Reverse transcription was carried out by adding AMV reverse transcriptase buffer, $4 \mathrm{mM}$ of dNTP, $15 \mathrm{U}$ of AMV reverse transcriptase, and $40 \mathrm{U}$ of RNAsin (all reagents from Promega) in a final reaction volume of $30 \mu \mathrm{L}$. The mixture was incubated for $1.5 \mathrm{~h}$ at $42^{\circ} \mathrm{C}$ and 5 min at $95^{\circ} \mathrm{C}$. Prior to use in $\mathrm{qPCR}, \mathrm{cDNA}$ was diluted 1:10 with RNase- and DNase-free water. Diluted cDNA samples were stored at $4^{\circ} \mathrm{C}$ until use.

Ten candidate genes were selected from previously used bovine reference genes (Goossens et al., 2005; Bionaz and Loor, 2007) and with the help of geNorm software(http://www.primerdesign.co.uk/geNormgenelists. html; Vandesompele et al., 2002; Table 1). The genes were chosen to belong to different functional classes, which reduces the probability that genes may be coregulated. All primers (Table 2) were designed using Clone Manager 9 (Scientific \& Educational Software, Cary, NC), using publicly available bovine sequences, 
Table 1. Names and functions of candidate reference genes

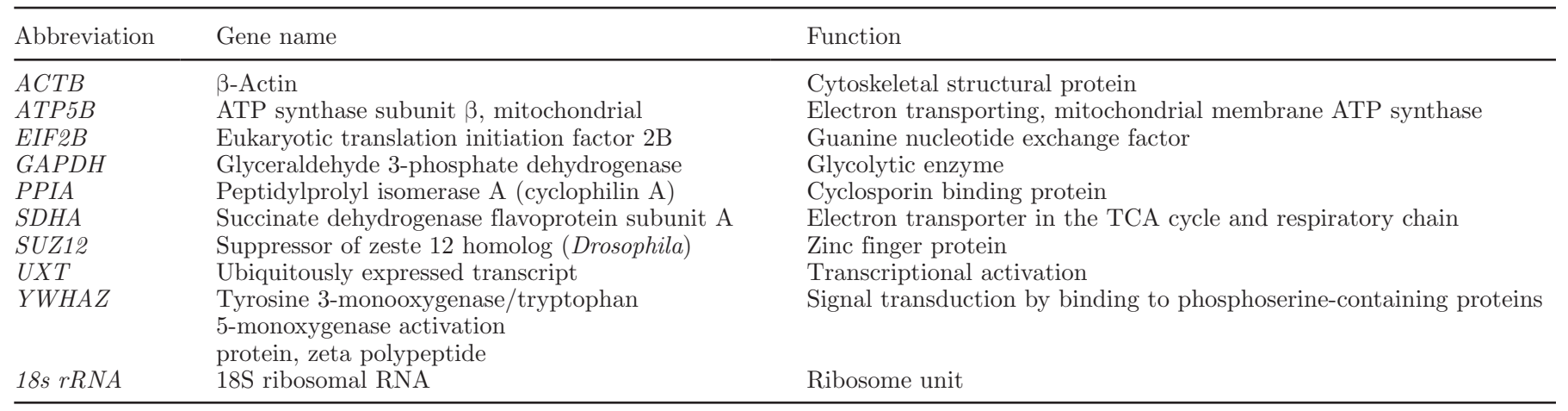

and were purchased from Eurogentec (Liège, Belgium). Primers were designed to span an intron-exon boundary to prevent amplification of genomic DNA. The secondary structure of the amplicon and SNP were analyzed with RTPrimer (http://www.rtprimerdb.org; Lefever et al., 2009). Then, primers and amplicon were verified in silico for specificity with BLASTN (http://blast.ncbi. nlm.nih.gov/Blast.cgi). The size of the PCR products was confirmed by using gel electrophoresis.

The PCR products were labeled with SYBR Green I fluorophore (Roche Diagnostics, Mannheim, Germany), which binds to the newly formed double-stranded DNA and whose fluorescence intensity is measured at the end of each elongation phase. The PCR was performed using a Bio-Rad Chromo 4 detection system (Bio-Rad, Hercules, CA) in a final volume of $12.5 \mu \mathrm{L}$, containing $2 \mu \mathrm{L}$ of cDNA sample (water was used as negative control), 1 $\mu \mathrm{L}$ of Titanium Taq Polymerase buffer $10 \times$ (Clontech, Le Pont de Claix, France), $2 \mathrm{mM} \mathrm{MgCl}$ (Promega), 0.2 $\mathrm{m} M$ dNTP (Promega), $0.25 \mathrm{~m} M$ of each primer pair (Eurogentec; Table 2), $0.5 \mu \mathrm{L}$ of SYBR Green I diluted at $1 / 1,000$, and $1 \mathrm{U}$ of Titanium Taq Polymerase (Clontech). The PCR included an initial denaturation step for $3 \mathrm{~min}$ at $95^{\circ} \mathrm{C}, 45$ cycles of denaturation for $3 \mathrm{~s}$ at $95^{\circ} \mathrm{C}$, annealing for $30 \mathrm{~s}$ at specific annealing temperature (Table 2), and elongation for $10 \mathrm{~s}$ at $72^{\circ} \mathrm{C}$. At the end of each run, a dissociation melt curve of the product was determined. All melt curves showed a single peak and were consistent with the presence of a single amplicon. For each sample set, the geometric mean was obtained and subtracted from each quantification cycle (Cq) value. The relative quantity $\left(2^{\Delta \mathrm{Cq}}\right.$; relative to other samples within the same run for the same gene) was then calculated and the file uploaded into geNorm

Table 2. Primer sequences for specific oligonucleotide primer pairs $(\mathrm{F}=$ forward, $\mathrm{R}=$ reverse $)$, annealing temperatures of primer set $\left({ }^{\circ} \mathrm{C}\right)$, expected amplicon size (bp), and accession number

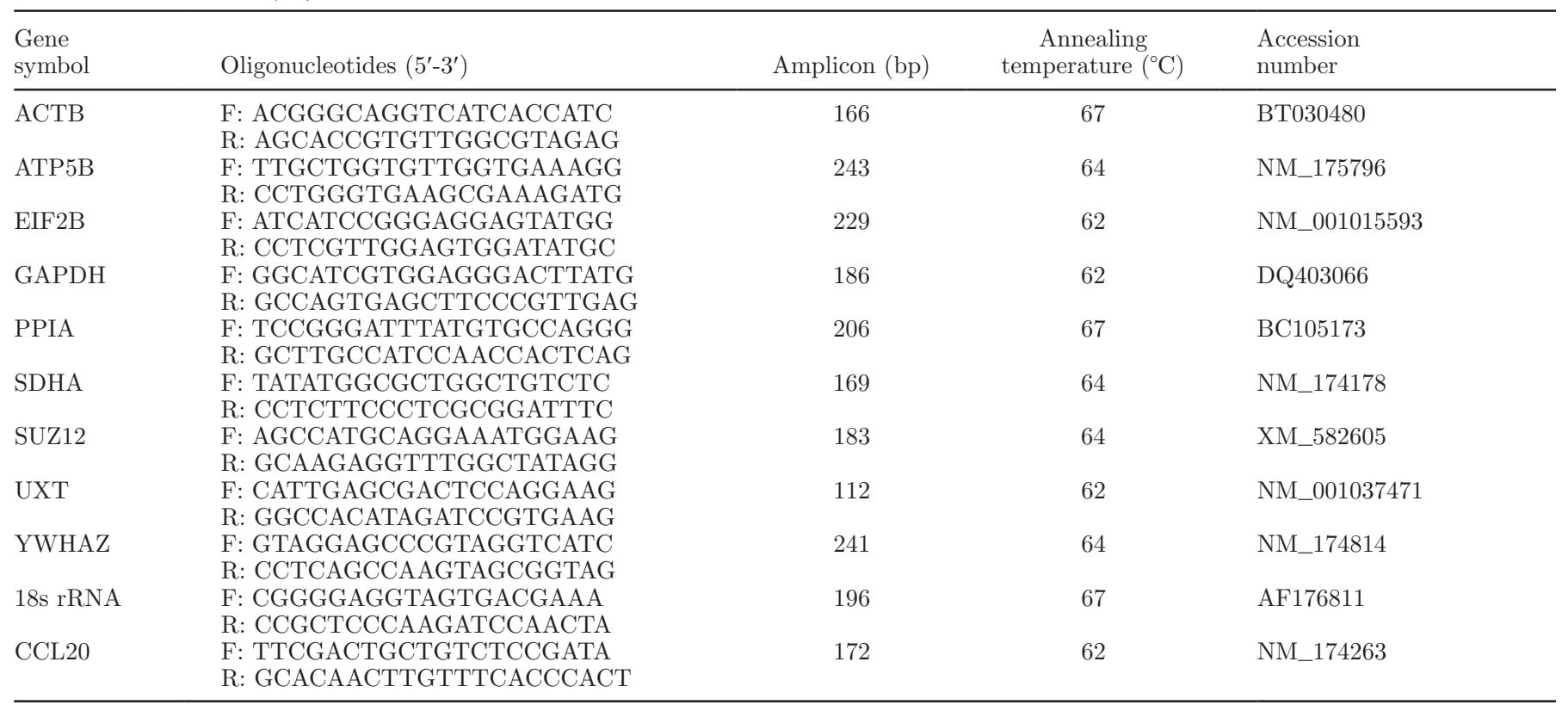




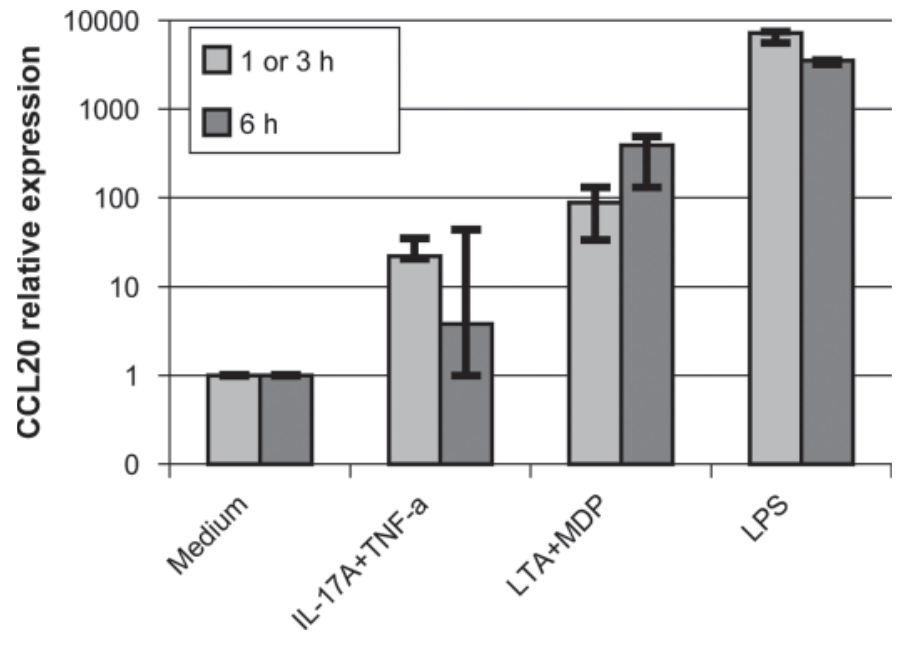

Figure 1. Expression of CCL20 [chemokine (C-C motif) ligand 20] mRNA by mammary epithelial cells (MEC) determined by reverse-transcription quantitative PCR. The MEC were left unstimulated (medium) or stimulated with cytokines [IL-17 + tumor necrosis factor- $\alpha$ (TNF-a)] or microbial-associated molecular pattern (lipoteichoic acid + muramyl dipeptide, LTA+MDP) for 1 and $6 \mathrm{~h}$, or with crude Escherichia coli LPS for 3 and $6 \mathrm{~h}$. Results are median values (first and third quartiles) from MEC of 5 cows.

to obtain the $M$ value corresponding to the stability of gene expression. This $M$ value is obtained by averaging the pairwise variation for each gene against other genes and then progressively excluding genes with the highest $M$ value (Vandesompele et al., 2002). The same gene was tested in the same PCR run with all the different samples to exclude inter-run variation, according to the gene maximization set-up (Derveaux et al., 2010). For each gene, the correlation coefficient of the standard curve was $>0.99$; PCR efficiency ranged from 85 to $110 \%$.

An initial screening by conventional RT-PCR of the expression pattern demonstrated that all genes were expressed in bMEC (data not shown). The responsiveness to various stimuli of the batches of MEC used in this study under our experimental conditions was established by measuring the expression of a set of genes by RT-qPCR. Several genes coding cytokines, chemokines, or antimicrobial peptides were upregulated [S. Bougarn, P. Cunha, F. Gilbert, A. Harmache, G. Foucras, and P. Rainard (all from INRA, Nouzilly, France), unpublished data]. As an illustration of the responsiveness of MEC, mRNA expression of the chemokine CCL20 is given in Figure 1. Then, gene expression levels of the candidate reference genes were measured by real-time PCR (expressed in Cq values) and analyzed in unstimulated and stimulated bMEC of 5 cows (Figure 2). The $\mathrm{Cq}$ values of the 10 genes in all the samples ranged between 9.12 (18s rRNA) and 26.04 (EIF2B). The Cq values had very low overall variability (Figure 2). Expression of

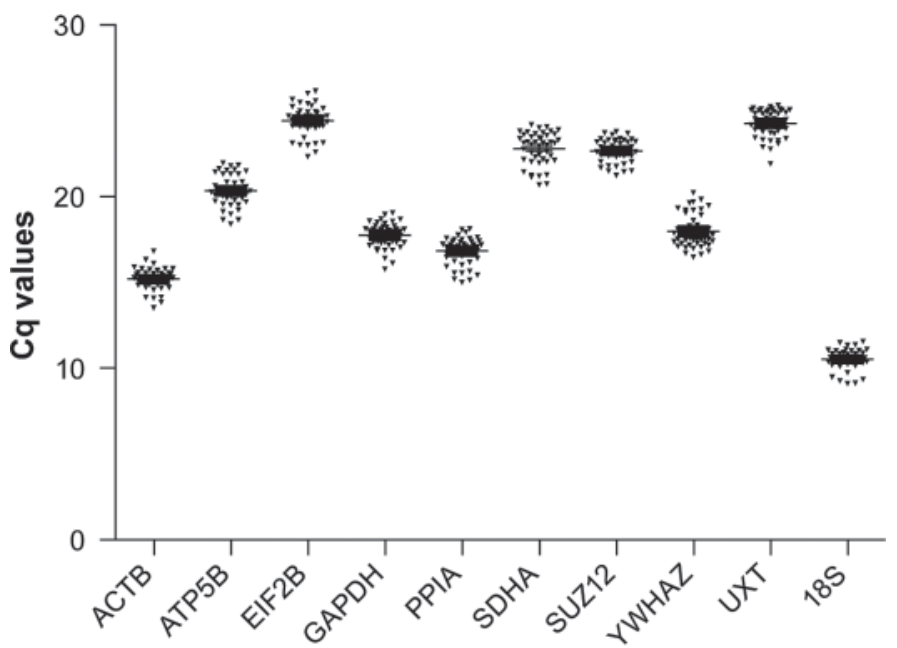

Reference genes

Figure 2. Expression levels of candidate reference genes (Table 1) in bovine mammary epithelial cells. Values are given as quantification cycle numbers $(\mathrm{Cq})$; each point is an individual $\mathrm{Cq}$ value. For each gene, the condensed "cloud" of 45 values $(5$ cows $\times 9$ culture conditions) shows that variations of $\mathrm{Cq}$ values were of limited magnitude.

ACTB, GAPDH, PPIA, SUZ12, and 18s rRNA was less variable than that of the other selected genes.

The expression of the 10 selected reference genes was analyzed under different experimental conditions of the bMEC stimulation: bacterial constituents (LTA+MDP, LPS), live bacteria (Staph. aureus and E. coli), or proinflammatory cytokines (IL-17A and TNF- $\alpha$ ), chosen as representative of infection and inflammation-associated stimuli. The gene expression stability measure $M$ was determined using the geNorm application to identify the most stable control genes in a set of sample. geNorm calculates an $M$ value for each gene based on pairwise comparisons of variability. The authors of the method indicate an $M$ value $<1.5$ as a cut-off for suitability as endogenous control genes (Vandesompele et al., 2002), and that with homogeneous samples (such as one celltype), $M$ values of stable genes are usually $<0.5$ (Hellemans et al., 2007). It is noteworthy that the $M$ values of all the reference genes evaluated in our study were $<0.5$, whatever the stimulus (Figure 3 ). The rank of genes varied from one stimulus to another, but overall all these genes can be considered as stably expressed under different stimulation conditions of the bMEC. Although GAPDH and $18 s$ rRNA have previously been used as reference genes for qPCR with stimulated MEC, they had not been validated (Wellnitz and Kerr, 2004; Lahouassa et al., 2007; Daly et al., 2009; GriesbeckZilch et al., 2009). The $18 s$ rRNA, GAPDH, SDHA, $U X T$, and $Y W H A Z$ genes have previously been found suitable as reference genes for bovine cells and tissues 

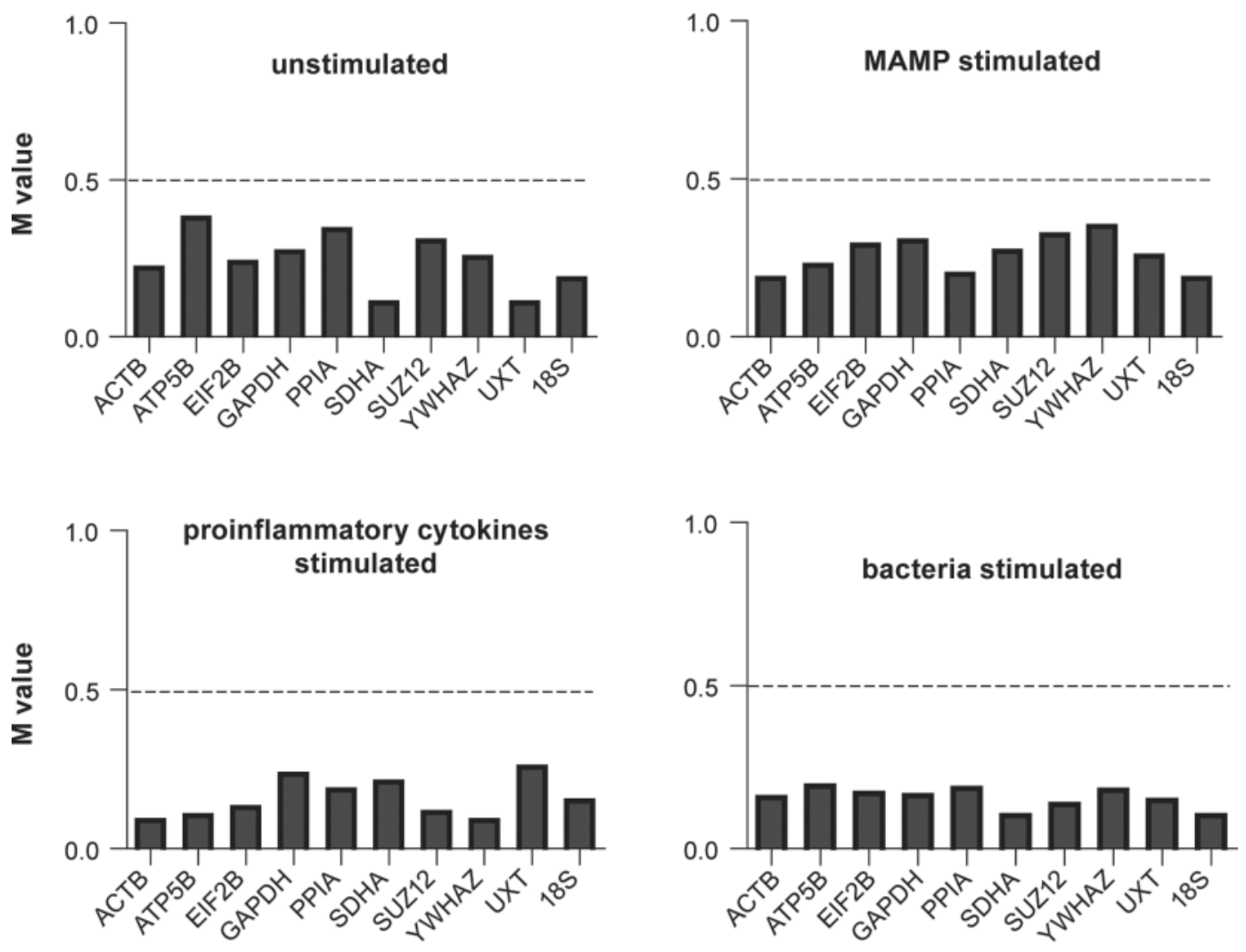

Reference genes

Reference genes

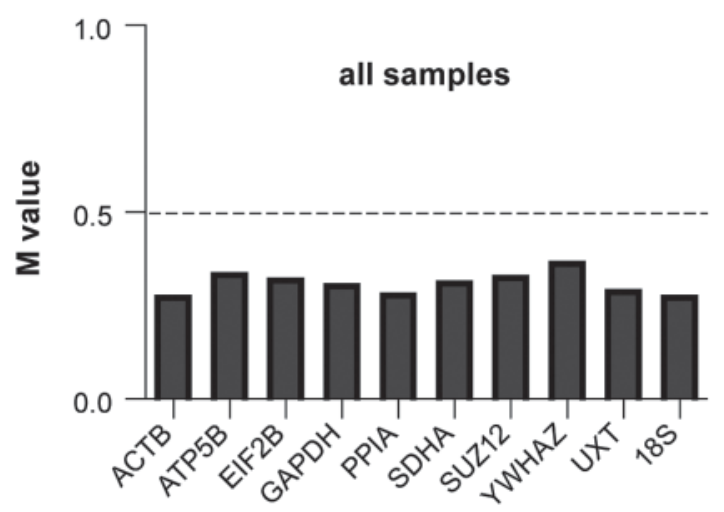

Reference genes

Figure 3. Gene expression stability of 10 potential reference genes (Table 1) in bovine mammary epithelial cells unstimulated or stimulated with various stimuli, analyzed by the geNorm program to yield the gene stability measure $M$ (the lower the value of $M$, the higher the gene stability). Stimulation was achieved with microbial-associated molecular pattern (MAMP; lipoteichoic acid + muramyl dipeptide, LTA+MDP), cytokines [IL-17 + tumor necrosis factor- $\alpha$ (TNF-a)], or bacteria (Staphylococcus aureus or Escherichia coli).

(Goossens et al., 2005; De Ketelaere et al., 2006; Bionaz and Loor, 2007). Our study extends these observations to 5 other genes and documents the suitability of 10 genes as reference genes for RT-qPCR.

In conclusion, using a combination of a few of the candidate reference genes tested herein is advisable for normalization of qPCR experiments carried out with confluent primary cultures of bMEC. To avoid the problem of reference gene expression instability as a function of experimental conditions, at least 3 genes should be used as internal control genes for normalization of qPCR data (Derveaux et al., 2010). One possibility 
could be to associate reference genes with different $\mathrm{Cq}$ values. These data will be useful in selecting reference genes and validating RT-qPCR data for use in bovine mastitis research.

\section{REFERENCES}

Bionaz, M., and J. J. Loor. 2007. Identification of reference genes for quantitative real-time PCR in the bovine mammary gland during the lactation cycle. Physiol. Genomics 29:312-319.

Bougarn, S., P. Cunha, A. Harmache, A. Fromageau, B. F. Gilbert, and P. Rainard. 2010. Muramyl dipeptide synergizes with Staphylococcus aureus lipoteichoic acid to recruit neutrophils in the mammary gland and to stimulate mammary epithelial cells. Clin. Vaccine Immunol. 17:1797-1809.

Bustin, S. A., V. Benes, J. A. Garson, J. Hellemans, J. Huggett, M. Kubista, R. Mueller, T. Nolan, M. W. Pfaffl, G. L. Shipley, J. Vandesompele, and C. T. Wittwer. 2009. The MIQE guidelines: Minimum information for publication of quantitative real-time PCR experiments. Clin. Chem. 55:611-622.

Bustin, S. A., V. Benes, T. Nolan, and M. W. Pfaffl. 2005. Quantitative real-time RT-PCR-A perspective. J. Mol. Endocrinol. 34:597-601.

Bustin, S. A., and T. Nolan. 2004. Pitfalls of quantitative real-time reverse-transcription polymerase chain reaction. J. Biomol. Tech. $15: 155-166$.

Daly, K. A., S. L. Mailer, M. R. Digby, C. Lefevre, P. Thomson, E. Deane, K. R. Nicholas, and P. Williamson. 2009. Molecular analysis of tammar (Macropus eugenii) mammary epithelial cells stimulated with lipopolysaccharide and lipoteichoic acid. Vet. Immunol. Immunopathol. 129:36-48.

De Ketelaere, A., K. Goossens, L. Peelman, and C. Burvenich. 2006. Technical note: Validation of internal control genes for gene expression analysis in bovine polymorphonuclear leukocytes. J. Dairy Sci. 89:4066-4069.

Derveaux, S., J. Vandesompele, and J. Hellemans. 2010. How to do successful gene expression analysis using real-time PCR. Methods $50: 227-230$.

Fleige, S., and M. W. Pfaffl. 2006. RNA integrity and the effect on the real-time qRT-PCR performance. Mol. Aspects Med. 27:126139.

Goldammer, T., H. Zerbe, A. Molenaar, H. J. Schuberth, R. M. Brunner, S. R. Kata, and H. M. Seyfert. 2004. Mastitis increases mam- mary mRNA abundance of beta-defensin 5, toll-like-receptor 2 (TLR2), and TLR4 but not TLR9 in cattle. Clin. Diagn. Lab. Immunol. 11:174-185.

Goossens, K., M. Van Poucke, A. Van Soom, J. Vandesompele, A. Van Zeveren, and L. J. Peelman. 2005. Selection of reference genes for quantitative real-time PCR in bovine preimplantation embryos. BMC Dev. Biol. 5:27.

Griesbeck-Zilch, B., M. Osman, C. Kuhn, M. Schwerin, R. H. Bruckmaier, M. W. Pfaffl, A. Hammerle-Fickinger, H. H. Meyer, and O. Wellnitz. 2009. Analysis of key molecules of the innate immune system in mammary epithelial cells isolated from marker-assisted and conventionally selected cattle. J. Dairy Sci. 92:4621-4633.

Hellemans, J., G. Mortier, A. De Paepe, F. Speleman, and J. Vandesompele. 2007. qBase relative quantification framework and software for management and automated analysis of real-time quantitative PCR data. Genome Biol. 8:R19.

Kadegowda, A. K., M. Bionaz, B. Thering, L. S. Piperova, R. A. Erdman, and J. J. Loor. 2009. Identification of internal control genes for quantitative polymerase chain reaction in mammary tissue of lactating cows receiving lipid supplements. J. Dairy Sci. 92:2007-2019

Lahouassa, H., E. Moussay, P. Rainard, and C. Riollet. 2007. Differential cytokine and chemokine responses of bovine mammary epithelial cells to Staphylococcus aureus and Escherichia coli. Cytokine 38:12-21.

Lefever, S., J. Vandesompele, F. Speleman, and F. Pattyn. 2009. RTPrimerDB: The portal for real-time PCR primers and probes. Nucleic Acids Res. 37(Database issue):D942-D945.

Strandberg, Y., C. Gray, T. Vuocolo, L. Donaldson, M. Broadway, and R. Tellam. 2005. Lipopolysaccharide and lipoteichoic acid induce different innate immune responses in bovine mammary epithelial cells. Cytokine 31:72-86.

Swanson, K. M., K. Stelwagen, J. Dobson, H. V. Henderson, S. R. Davis, V. C. Farr, and K. Singh. 2009. Transcriptome profiling of Streptococcus uberis-induced mastitis reveals fundamental differences between immune gene expression in the mammary gland and in a primary cell culture model. J. Dairy Sci. 92:117-129.

Vandesompele, J., K. De Preter, F. Pattyn, B. Poppe, N. Van Roy, A. De Paepe, and F. Speleman. 2002. Accurate normalization of realtime quantitative RT-PCR data by geometric averaging of multiple internal control genes. Genome Biol. 3:RESEARCH0034.

Wellnitz, O., and D. E. Kerr. 2004. Cryopreserved bovine mammary cells to model epithelial response to infection. Vet. Immunol. Immunopathol. 101:191-202. 